\title{
Effect of ARDS Severity and Etiology on Short-Term Outcomes
}

\author{
Haitham El-Haddad MD, Hyejeong Jang MSc, Wei Chen PhD, and Ayman O Soubani MD
}

\begin{abstract}
BACKGROUND: We evaluated the outcome of subjects with ARDS in relation to etiology and severity in a retrospective cohort study of the ARDS Network randomized controlled trials. The primary outcome was 28-d mortality. The secondary outcomes were 60-d mortality and ventilatorand ICU-free days. For severity of ARDS, subjects were stratified according to $\mathrm{P}_{\mathrm{aO} 2} / \mathrm{F}_{\mathrm{IO} 2}$. The etiology of ARDS was classified into sepsis, pneumonia, aspiration, trauma, and others. RESULTS: A total of 2,914 subjects were included in these trials. Outcomes were modeled with multivariable regressions adjusted for baseline covariates, age, sex, race, Acute Physiology and Chronic Health Evaluation III (APACHE III), vasopressor use, modified lung injury score, diabetes mellitus, cancer status, body mass index, pre-ICU location, ICU location, and study. There was no statistically significant difference in 28-d mortality in relation to ARDS severity. Subjects with trauma, compared with other etiologies of ARDS, had significantly lower mortality at $28 \mathrm{~d}$ (odds ratio $[\mathrm{OR}]=0.47$, 95\% CI $0.26-0.83, P=.01)$. Sixty-day mortality was significantly lower for trauma subjects and those with severe ARDS group $(\mathrm{OR}=0.5,95 \% \mathrm{CI} 0.3-0.85, P=.01$ and $\mathrm{OR}=0.71,95 \% \mathrm{CI}$ $0.52-0.98, P=.034$, respectively). There were statistically significantly more ICU-free days and ventilator-free days for the aspiration group $(\mathrm{OR}=1.09,95 \% \mathrm{CI} 1.02-1.17, P=.01$ and $\mathrm{OR}=1.09$, 95\% CI 1.02-1.16, $P=.01$, respectively). There was no statistically significant difference in ICUfree days or ventilator-free days in relation to severity of ARDS. CONCLUSIONS: Severity of ARDS based on $\mathrm{P}_{\mathrm{aO} 2} / \mathrm{F}_{\mathrm{IO} 2}$ did not impact 28-d mortality, ventilator-free days, or ICU-free days. Among the etiologies of ARDS, trauma subjects had the lowest 28- and 60-d mortality, whereas subjects with aspiration had more ICU-free days and ventilator-free days. Key words: ARDS; outcome; etiology; severity. [Respir Care 2017;62(9):1178-1185. (C) 2017 Daedalus Enterprises]
\end{abstract}

\section{Introduction}

ARDS is a constellation of pathophysiologic changes associated with an early acute lung injury that results in increased capillary leak and pulmonary edema. Clinically, patients manifest with hypoxemia, diffuse radiographic pulmonary infiltrates, and decreased lung compliance. In the

Drs El-Haddad and Soubani are affiliated with the Division of Pulmonary, Critical Care, and Sleep Medicine, and Ms Jang and Dr Chen are affiliated with the Department of Oncology, Wayne State University School of Medicine, Detroit, Michigan.

The authors have disclosed no conflicts of interest.

Correspondence: Ayman O Soubani MD, Division of Pulmonary, Critical Care, and Sleep Medicine, Wayne State University School of Medicine, Harper University Hospital, 3990 John R-3 Hudson, Detroit, MI 48201. E-mail: asoubani@med.wayne.edu.

DOI: $10.4187 /$ respcare. 05403
United States, it is estimated that there are 150,000 cases of ARDS annually with a mortality of $40-50 \% .^{1}$

There are conflicting results in the literature about the predictors of outcome in patients with ARDS. Factors such as age and the diagnosis of cancer are associated with poor outcome, but not sex, body mass index, diagnosis of diabetes mellitus, or location of the patient. . $^{-4}$ There are few data on the role of etiology and severity of ARDS upon presentation on different outcomes of patients, and these also show variable results. ${ }^{5-7}$ The purpose of this study is to analyze the ARDS Network randomized controlled trials database to determine whether etiology and severity of ARDS affected the short-term outcomes of these subjects.

\section{Methods}

The ARDS Network has conducted several randomized controlled trials to evaluate therapeutic interventions in the management of ARDS. These trials have 
been previously published. ${ }^{8-13}$ Table 1 summarizes the relevant features of these trials. Briefly, all subjects fulfilled diagnostic criteria for ARDS and were mechanically ventilated. Similar inclusion and exclusion criteria were used in all of the trials. The National Institutes of Health and the local institutional review boards of each of the sites approved all studies.

We had authorized access to the original data for each of these studies. This paper was prepared using the KARMA (ketoconazole and respiratory management in acute lung injury (ALI)/ARDS), LaSRS (late steroid rescue study), LARMA (lisofylline and respiratory management in ALI/ARDS), ALVEOLI (assessment of low tidal volume and elevated end-expiratory volume to obviate lung injury), FACTT (fluids and catheters treatment trial), and ALTA (albuterol for the treatment of acute lung injury) research materials obtained from the National Heart, Lung, and Blood Institute Biologic Specimen and Data Repository Information Coordinating Center. The primary objective of the KARMA trial was to investigate the efficacy and safety of ketoconazole and respiratory management in the treatment of ALI and ARDS. The ketoconazole arm of the study was later stopped due to an inability to show efficacy. Subjects continued to be randomized to the respiratory management arms of the study (ARMA), which compared 2 ventilator strategies: a tidal volume of $6 \mathrm{~mL} / \mathrm{kg}$ versus $12 \mathrm{~mL} / \mathrm{kg}$ (https:// biolincc.nhlbi.nih.gov/studies/ardsnet/, Accessed February 27, 2017). The subjects reported in ARMA $(N=861)$ were a combination of those from KARMA $(N=667)$ and LARMA $(N=194)^{8}$ (https://biolincc.nhlbi.nih.gov/ studies/ardsnet/, Accessed February 27, 2017). The findings of the current study do not necessarily reflect the opinions or views of the KARMA, LASRS, LARMA, ALVEOLI, FACTT, and ALTA investigators or the National Heart, Lung, and Blood Institute. For the purpose of this analysis, we included only subjects who had $\mathrm{P}_{\mathrm{aO}_{2}} / \mathrm{F}_{\mathrm{IO}_{2}} \leq 300$ to fulfill the Berlin definition of ARDS. ${ }^{14}$

The 2 variables that we are studying are the severity as well as the etiology of ARDS. The severity was stratified according to $\mathrm{P}_{\mathrm{aO}_{2}} / \mathrm{F}_{\mathrm{IO}_{2}}$ into mild $\left(\mathrm{P}_{\mathrm{aO}_{2}} / \mathrm{F}_{\mathrm{IO}_{2}}=200-300\right)$, moderate $\left(\mathrm{P}_{\mathrm{aO}_{2}} / \mathrm{F}_{\mathrm{IO}_{2}}=100\right.$ to $\left.<200\right)$, and severe $\left(\mathrm{P}_{\mathrm{aO}_{2}} / \mathrm{F}_{\mathrm{IO}_{2}}<100\right)$ as per the Berlin definition of ARDS. The etiology was classified based on the original ARDS Network trials' determination into pneumonia, aspiration, trauma, sepsis, and others.

\section{Statistical Analysis}

Descriptive statistics for subject baseline characteristics were summarized within each of the 6 studies. The authors made every effort to ensure that each subject was unique and that there were no overlaps between the different studies. Medians with ranges were reported for continuous data, whereas frequencies and percentages were reported

\section{QUICK LOOK}

\section{Current knowledge}

ARDS remains a major problem in critically ill patients with high mortality. There are conflicting data in the literature about predictors of outcome in subjects with ARDS.

\section{What this paper contributes to our knowledge}

Analysis of the ARDS Network robust database shows that severity of ARDS based on $\mathrm{P}_{\mathrm{aO}_{2}} / \mathrm{F}_{\mathrm{IO}_{2}}$ did not predict short-term outcome of these subjects and that trauma was associated with better outcome compared with other causes of ARDS.

for categorical data. The primary objective for our study was mortality at $28 \mathrm{~d}$ after enrollment in the study in relation to severity and etiology of ARDS. Covariates in the multivariable regressions included age $(<60$ and $\geq 60)$, sex, ethnicity (white, black, and other), pre-ICU location, type of ICU, Acute Physiology and Chronic Health Evaluation III (APACHE III), vasopressor use, cause of lung injury (pneumonia, sepsis, aspiration, trauma, and others), modified lung injury score, cancer status, body mass index, diabetes mellitus, and study. These variables were specified a priori to be clinically sound or based on our previous publications. ${ }^{2-4}$ The commonly used measure of acute lung injury score was proposed in 1988 by Murray et al. ${ }^{15}$ The score is composed of 4 components: (1) chest radiograph; (2) $\mathrm{P}_{\mathrm{aO}_{2}} / \mathrm{F}_{\mathrm{IO}}$; (3) PEEP; and (4) lung compliance. We proposed the modified lung injury score in this study by excluding the $\mathrm{P}_{\mathrm{aO}} / \mathrm{F}_{\mathrm{IO}_{2}}$ component. We added individual scores for each category and then divided by the number of components used. Hence, the $\mathrm{P}_{\mathrm{aO}_{2}} / \mathrm{F}_{\mathrm{IO}_{2}}$ was reported independently in our study because it is one of the variables of interest for this work. The secondary clinical outcomes evaluated were 60 -d mortality, ventilator-free days, and ICU-free days. The ventilator-free days were defined as the number of days of at least 48-h unassisted breathing during the first $28 \mathrm{~d}$ after enrollment.

The univariate analysis of association between our variable of interest, namely severity and etiology of ARDS, and clinical outcomes, including 28-d mortality, 60-d mortality, categorized ventilation-free days in weeks, and categorized ICU-free days in weeks, were performed for statistical significance using a chi-square test or Fisher exact test where appropriate. In-hospital mortality curves for the 3 subgroups of severity of hypoxemia were constructed with the cumulative incidence function method using discharge as competing events.

A multivariable logistic regression model and multivariable zero-inflated negative binomial regression 


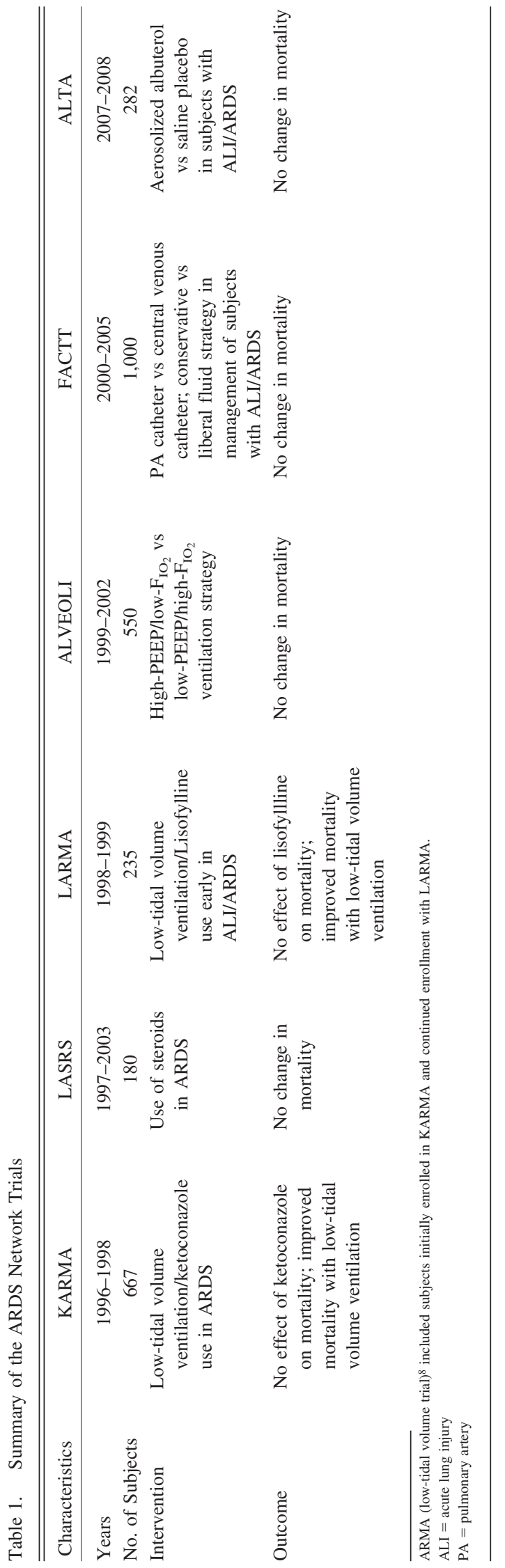

model were then used to evaluate the effect of severity and etiology of ARDS on clinical outcomes, including 28 -d mortality or 60-d mortality and ventilation-free days or ICU-free days, respectively. All $P$ values are 2 -sided with a significance level of .05. The results of these analyses should be regarded only as exploratory findings, and raw $P$ values were reported without adjustment for multiple testing. All calculations were performed with R 3.2.2.

\section{Results}

A total of 2,914 subjects were included in these trials. Five subjects with $\mathrm{P}_{\mathrm{aO}_{2}} / \mathrm{F}_{\mathrm{IO}_{2}}>300$ and 2 with missing data were excluded from analysis. Table 2 describes the baseline characteristics of these subjects.

Based on univariate analysis, there were significant differences in 28-d mortality between the different etiologies of ARDS (Fig. 1A). The highest mortality was with sepsis (32.29\%), followed by pneumonia (24.91\%), other causes $(24.14 \%)$, aspiration $(23.06 \%)$, and trauma $(8.81 \%)$. The differences between these groups were significant $(P<.001$, chi-square test $)$. Similar associations were observed with 60-d mortality (Fig. 1A). For the severity of ARDS based on $\mathrm{P}_{\mathrm{aO}_{2}} / \mathrm{F}_{\mathrm{IO}_{2}}$, there were significant differences in 28-d mortality, with the highest mortality in severe ARDS (28.61\%), followed by moderate ARDS (22.75\%) and mild ARDS (22.17\%) $(P=.001$, chi-square test $)$. Similar associations were observed with 60-d mortality (Fig. 1B). Higher mortality acceleration was observed in the severely hypoxemic group within $28 \mathrm{~d}$ (Fig. 2). The early phase of accelerated mortality leveled off between 28 and $60 \mathrm{~d}$. Then the hospital mortality rate plateaued after $60 \mathrm{~d}$.

Univariate analysis of other secondary outcomes also revealed that ventilator-free days and ICU-free days were most frequent in the case of aspiration and lowest with sepsis (Figs. 3A and 4A) and did not follow a specific pattern in relation to $\mathrm{P}_{\mathrm{aO}} / \mathrm{F}_{\mathrm{IO}_{2}}$ (Figs. 3B and 4B).

On multivariable analysis of outcomes to assess the role of etiology and severity, the following variables were included as covariates: age, sex, race, APACHE III, modified acute lung injury score, vasopressor use, diabetes mellitus, cancer status, body mass index, pre-ICU location, ICU location, and study. With sepsis as the reference variable, trauma had significantly lower 28- and 60-d mortality (odds ratio $[\mathrm{OR}]=0.47,95 \% \mathrm{CI} 0.26-0.83, P=.01$ and $\mathrm{OR}=0.5,95 \% \mathrm{CI} 0.3-0.85, P=.01$, respectively) (Table 3). As for the severity of ARDS, with mild serving as reference, there were no significant differences in 28-d mortality; however, subjects with severe ARDS had significantly lower 60 -d mortality $(\mathrm{OR}=0.71,95 \%$ CI $0.53-$ $0.98, P=.034)$. 
EFFect of ARDS SeVERIty AND Etiology on Outcomes

Table 2. Baseline Subject Characteristics by Study

\begin{tabular}{|c|c|c|c|c|c|c|}
\hline Variable & $\begin{array}{l}\text { KARMA } \\
(N=667)\end{array}$ & $\begin{array}{c}\text { LASRS } \\
(N=180)\end{array}$ & $\begin{array}{l}\text { LARMA } \\
(N=235)\end{array}$ & $\begin{array}{l}\text { ALVEOLI } \\
(N=550)\end{array}$ & $\begin{array}{c}\text { FACTT } \\
(N=1,000)\end{array}$ & $\begin{array}{c}\text { ALTA } \\
(N=282)\end{array}$ \\
\hline Age, median (range) y & $51(18-89)$ & $47(16-89)$ & $49(18-86)$ & $50(16-88)$ & $49(17-89)$ & $52(17-89)$ \\
\hline \multicolumn{7}{|l|}{ Sex, $n(\%)$} \\
\hline Male & $392(59)$ & $89(49)$ & $145(62)$ & $302(55)$ & $534(53)$ & $156(55)$ \\
\hline Female & $275(41)$ & $91(51)$ & $90(38)$ & $248(45)$ & $466(47)$ & $126(45)$ \\
\hline \multicolumn{7}{|l|}{ Race, $n(\%)$} \\
\hline White & $482(72)$ & $131(73)$ & $179(76)$ & $413(75)$ & $641(64)$ & $217(77)$ \\
\hline Black & $118(18)$ & $28(16)$ & 37 (16) & 77 (14) & $217(22)$ & $46(16)$ \\
\hline Others & $67(10)$ & $21(12)$ & $19(8)$ & $60(11)$ & $142(14)$ & $19(7)$ \\
\hline \multicolumn{7}{|l|}{ Vasopressor use, $n(\%)$} \\
\hline Yes & $269(40)$ & $56(31)$ & $78(33)$ & $156(28)$ & $330(33)$ & $141(50)$ \\
\hline Missing & $3(0.45)$ & $2(1.11)$ & $2(0.85)$ & $18(3.27)$ & $1(0.1)$ & $0(0)$ \\
\hline \multicolumn{7}{|l|}{ Cause of lung injury, $n(\%)$} \\
\hline Sepsis & $178(27)$ & $36(20)$ & $58(25)$ & $120(22)$ & $233(23)$ & $77(27)$ \\
\hline Pneumonia & $205(31)$ & $63(35)$ & $84(36)$ & $221(40)$ & $471(47)$ & $107(38)$ \\
\hline Aspiration & $96(14)$ & $30(17)$ & $38(16)$ & $85(15)$ & $149(15)$ & $54(19)$ \\
\hline Trauma & $74(11)$ & $23(13)$ & $22(9)$ & $45(8)$ & $74(7)$ & $23(8)$ \\
\hline Others & $114(17)$ & $28(16)$ & $33(14)$ & $79(14)$ & $73(7)$ & $21(7)$ \\
\hline \multicolumn{7}{|l|}{$\mathrm{P}_{\mathrm{aO}_{2}} / \mathrm{F}_{\mathrm{IO}_{2}}, n(\%)$} \\
\hline Mild & $100(15)$ & $0(0)$ & $26(11)$ & $72(13)$ & $157(16)$ & $51(18)$ \\
\hline Moderate & $320(48)$ & $118(66)$ & $125(53)$ & $270(49)$ & $459(46)$ & $129(46)$ \\
\hline Severe & $247(37)$ & $61(34)$ & $82(35)$ & $208(38)$ & $381(38)$ & $101(36)$ \\
\hline$>300 *$ & $0(0)$ & $0(0)$ & $1(0)$ & $0(0)$ & $3(0)$ & $1(0)$ \\
\hline Missing & $0(0)$ & $1(1)$ & $1(0)$ & $0(0)$ & $0(0)$ & $0(0)$ \\
\hline Modified LIS, median (range) & $2.5(0.67-4)$ & $3.33(2-4)$ & $2.5(0-4)$ & $2.67(0.67-4)$ & $2.67(0-4)$ & $2.5(0-4)$ \\
\hline APACHE III, median (range) & $81(22-178)$ & $85.5(16-155)$ & $86(30-195)$ & $91(0-191)$ & $91(17-205)$ & $90.5(32-185)$ \\
\hline
\end{tabular}
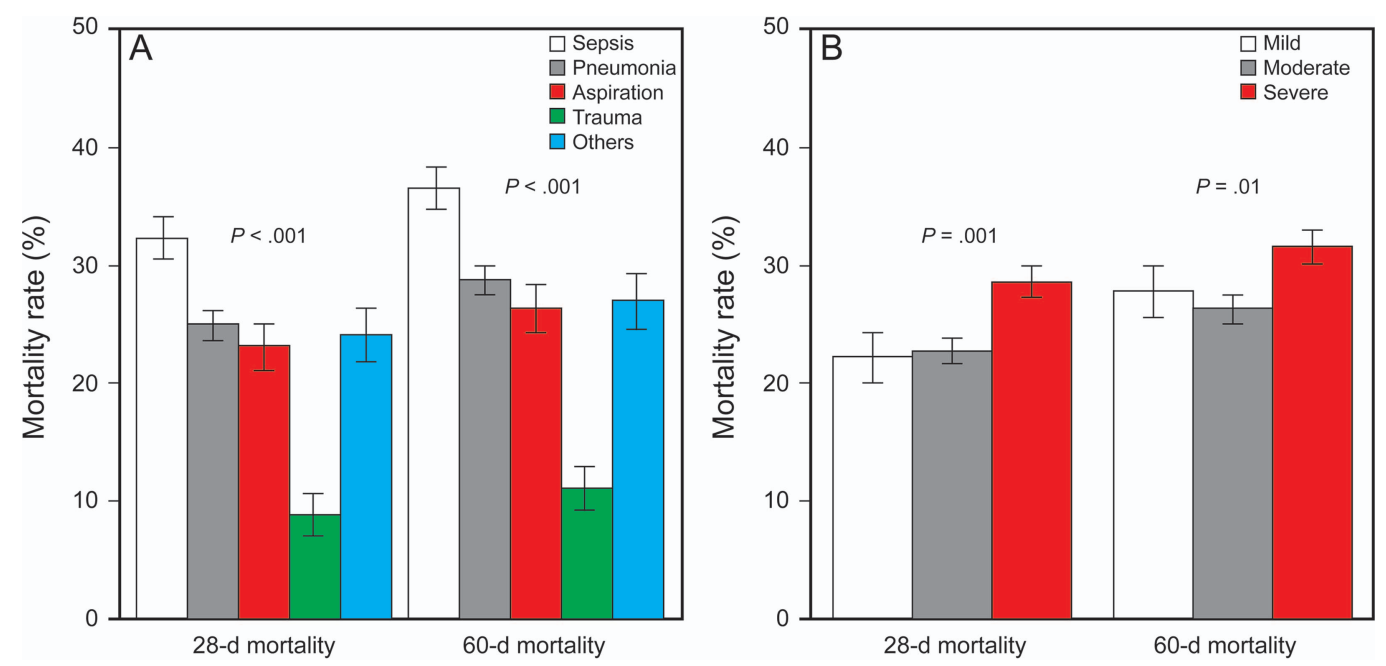

Fig. 1. Mortality rate by cause of lung injury $(A)$, and $\mathrm{P}_{\mathrm{aO}_{2}} / \mathrm{F}_{1 \mathrm{O}_{2}}$ (B). Chi-squared test was used to calculate $P$ values. Bars show mortality rate \pm SD from subgroups defined by each variable. Chi-squared test was used to test the association between the mortalities (alive or dead) and cause of lung injury (sepsis, pneumonia, aspiration, trauma, and other) for $\mathrm{A}$ and association between mortalities and $\mathrm{P}_{\mathrm{aO}} / \mathrm{F}_{\mathrm{IO}_{2}}$ (mild, moderate, and severe) for B. 


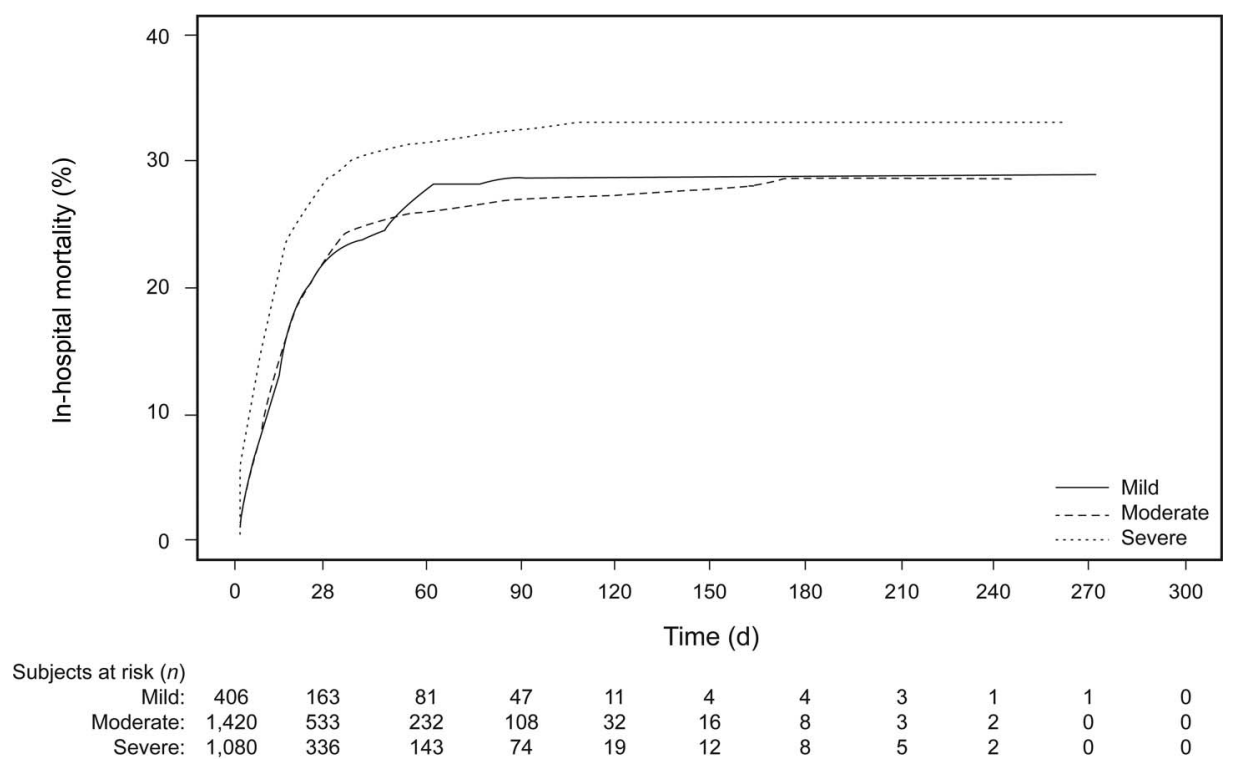

Fig. 2. Cumulative incidence of in-hospital mortality by $\mathrm{P}_{\mathrm{aO}_{2}} / \mathrm{F}_{\mathrm{IO}_{2}}$ category.
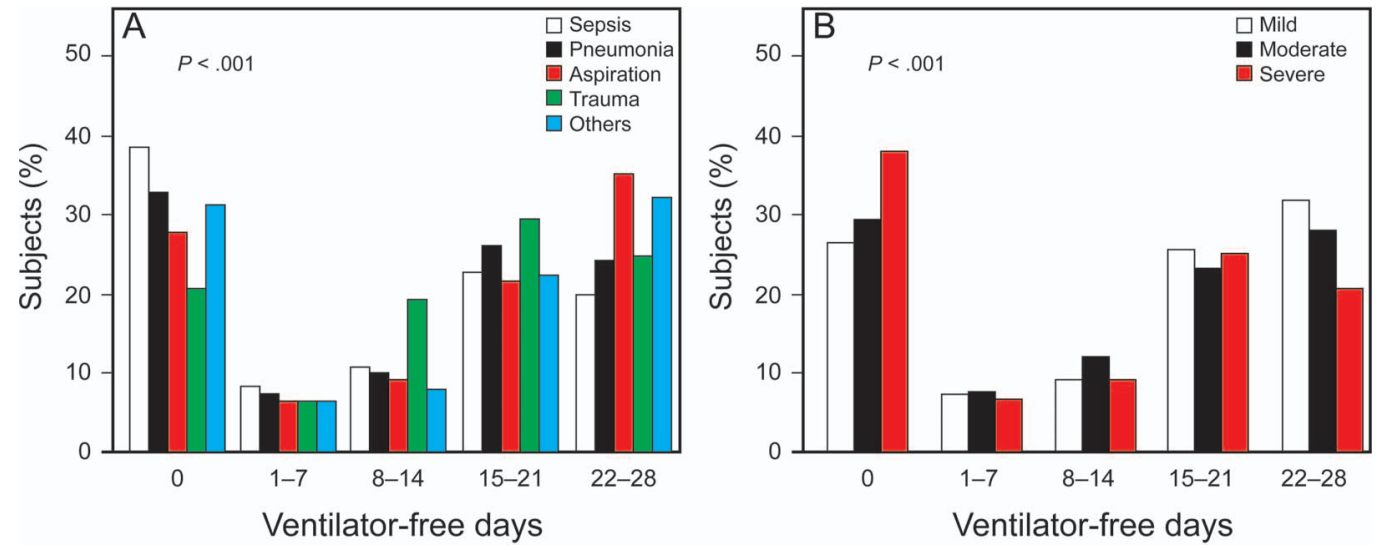

Fig. 3. Percentage of subjects with $0,1-7,8-14,15-21$, and 22-28 categorized ventilator-free days during the first $28 \mathrm{~d}$ after enrollment by cause of lung injury $(A)$, and $\mathrm{P}_{\mathrm{aO}_{2}} / \mathrm{F}_{\mathrm{IO}_{2}}$ ratio $(\mathrm{B})$; chi-squared test was used to test the association between the categorized ventilator-free days and cause of lung injury (sepsis, pneumonia, aspiration, trauma, and other) for $\mathrm{A}$ and association between categorized ventilator-free days and $\mathrm{P}_{\mathrm{aO}_{2}} / \mathrm{F}_{\mathrm{IO}_{2}}$ (mild, moderate, and severe) for $\mathrm{B}$.

Also, trauma was associated with the lowest ICUfree days $(\mathrm{OR}=0.9,95 \%$ CI $0.83-0.99, P=.02)$. Aspiration had higher ICU- and ventilator-free days $(\mathrm{OR}=1.09,95 \% \mathrm{CI} 1.02-1.17, P=.01$ and $\mathrm{OR}=1.09$, 95\% CI 1.02-1.16P=.01, respectively) (Table 3). There were no significant differences between the severity of ARDS in relation to ventilator- and ICU-free days (Table 3).

\section{Discussion}

The current analysis of the ARDS Network trials was conducted to determine the effect of etiology and severity of ARDS on short-term patient outcomes. It shows that trauma had the lowest 28- and 60-d mortality; it was also associated with the lowest ICU-free days. Aspiration was associated with higher ventilator- and ICU-free days. There were no significant differences between other etiologies of ARDS. Using $\mathrm{P}_{\mathrm{aO}_{2}} / \mathrm{F}_{\mathrm{IO}_{2}}$ as a surrogate for severity of ARDS, there were no differences in 28-d mortality or ventilatoror ICU-free days. Subjects with severe ARDS had lower 60-d mortality.

The impact of etiology of ARDS on outcome has been previously studied with variable and sometimes contradictory results.., 6 The current study shows that there is no difference in mortality between the different etiologies of ARDS except for trauma, which was associated with better prognosis. This finding is consistent with other studies..$^{5}$ A meta-analysis of 

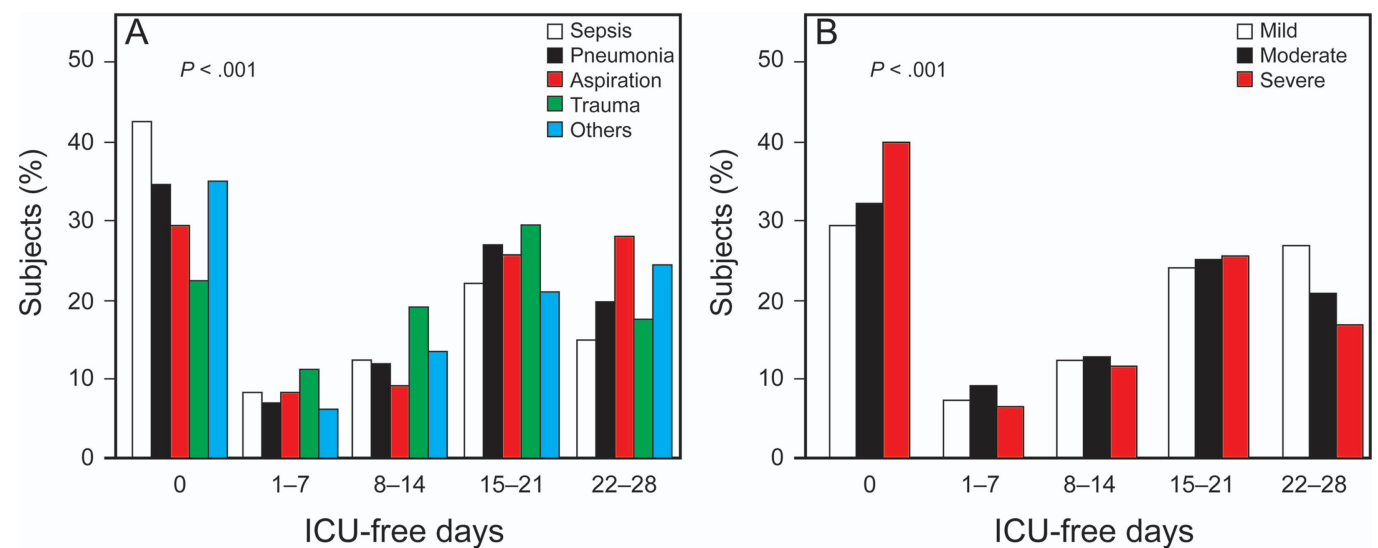

Fig. 4. Percentage of subjects with $0,1-7,8-14,15-21$, and 22-28 categorized ICU-free days during the first $28 \mathrm{~d}$ after enrollment by cause of lung injury (A) and $\mathrm{P}_{\mathrm{aO}_{2}} / \mathrm{F}_{\mathrm{IO}_{2}}(\mathrm{~B})$; chi-squared test was used to test the association between the categorized ICU-free days and cause of lung injury (sepsis, pneumonia, aspiration, trauma, and other) for $\mathrm{A}$ and association between categorized $\mathrm{ICU}_{\text {-free }}$ days and $\mathrm{P}_{\mathrm{aO}}{ }_{2} / \mathrm{F}_{\mathrm{IO}_{2}}(\mathrm{mild}$, moderate, and severe) for $B$.

Table 3. Results of Multivariable Regression Models

\begin{tabular}{|c|c|c|c|c|c|c|c|c|}
\hline \multirow{2}{*}{ Characteristics } & \multicolumn{2}{|c|}{ 28-d Mortality* } & \multicolumn{2}{|c|}{ 60-d mortality* } & \multicolumn{2}{|c|}{ ICU-Free Days $\dagger$} & \multicolumn{2}{|c|}{ Ventilator-Free Days $\dagger$} \\
\hline & OR $(95 \% \mathrm{CI})$ & $P$ & OR $(95 \% \mathrm{CI})$ & $P$ & $\mathrm{RR}(95 \% \mathrm{CI})$ & $P$ & $\mathrm{RR}(95 \% \mathrm{CI})$ & $P$ \\
\hline \multicolumn{9}{|l|}{ Cause of lung injury } \\
\hline Sepsis & Reference & & Reference & & Reference & & Reference & \\
\hline Pneumonia & $0.98(0.76-1.27)$ & .88 & $0.99(0.77-1.26)$ & .91 & $1.02(0.96-1.07)$ & .60 & $1.01(0.96-1.06)$ & .73 \\
\hline Aspiration & $0.84(0.61-1.17)$ & .31 & $0.8(0.58-1.1)$ & .17 & $1.09(1.02-1.17)$ & .01 & $1.09(1.02-1.16)$ & .01 \\
\hline Trauma & $0.47(0.26-0.83)$ & .01 & $0.5(0.3-0.85)$ & .01 & $0.9(0.83-0.99)$ & .03 & $0.93(0.86-1.02)$ & .12 \\
\hline Others & $1.09(0.77-1.54)$ & .62 & $1.03(0.74-1.44)$ & .86 & $1.07(0.99-1.15)$ & .08 & $1.06(0.99-1.13)$ & .12 \\
\hline \multicolumn{9}{|l|}{$\mathrm{P}_{\mathrm{aO}_{2}} / \mathrm{F}_{\mathrm{IO}_{2}}$} \\
\hline Mild & Reference & & Reference & & Reference & & Reference & \\
\hline Moderate & $0.86(0.63-1.19)$ & .36 & $0.75(0.55-1.01)$ & .055 & $0.94(0.89-1)$ & .058 & $0.95(0.9-1.01)$ & .11 \\
\hline Severe & $0.87(0.63-1.22)$ & .42 & $0.71(0.52-0.98)$ & .034 & $0.98(0.92-1.05)$ & .54 & $0.98(0.92-1.04)$ & .47 \\
\hline $\begin{array}{l}\text { Each model was adjusted } \\
\text { location, and study. } \\
* \text { Multivariable logistic } \mathrm{r} \\
\dagger \text { Multivariable zero-infla } \\
\mathrm{OR}=\text { (adjusted) odds rat } \\
\mathrm{RR}=\text { only (adjusted) rat }\end{array}$ & $\begin{array}{l}\text { line covariates, age, sex, } \\
\text { tive binomial regression. } \\
\text { I count component is sh }\end{array}$ & ere & III, vasopressor use, $\mathrm{m}$ & & ore, diabetes mellitt & & mass index, pre-ICU & \\
\hline
\end{tabular}

34 studies was performed to determine the difference in outcome (mortality) between subjects with pulmonary and extrapulmonary causes of ARDS. There was no difference in mortality between the 2 groups (OR of mortality in pulmonary ARDS group compared with the extrapulmonary ARDS group was 1.11 (95\% CI 0.88-1.39). ${ }^{6}$ In the case ARDS in the setting of trauma, earlier studies suggested that it has worse prognosis; however, other reports show better outcomes. ${ }^{16,17}$ The current study of a large and robust database confirms better mortality outcomes for trauma patients but lower ICU-free days.

The better outcome in subjects with ARDS and trauma compared with other groups may be related to multiple factors, including younger age, no co-morbid illnesses, improved ICU care, and the possibility that earlier studies included subjects who had trauma and other complications, such as sepsis, which increased their risk of dying. Also, ARDS in patients with trauma may be in part related to fluid resuscitation and massive transfusions, which are usually associated with fewer inflammatory changes than sepsis or aspiration. ${ }^{18}$ Furthermore, there is evidence that the severity of lung endothelial and alveolar epithelial injury in ARDS from major trauma appears to be less than that of other clinical disorders associated with acute lung injury. ${ }^{19,20}$

The implications of potential differences in outcome in relation to the etiology of ARDS are that different diseases may respond differently to therapeutic interventions. However, this theory was not demonstrated in previous studies, including the ARDS Network trials (Table 1). In a study 
that specifically reviewed the efficacy of low tidal volume in different etiologies of ARDS, there was no difference in outcome. ${ }^{21}$

Another important finding of this analysis is that the primary outcome of ARDS is not affected by $\mathrm{P}_{\mathrm{aO}_{2}} / \mathrm{F}_{\mathrm{IO}_{2}}$ at the time of enrollment. Also, there were no differences in ventilator- and ICU-free days but lower 60-d mortality in subjects with severe ARDS $\left(\mathrm{P}_{\mathrm{aO}_{2}} / \mathrm{F}_{\mathrm{IO}_{2}}<100\right)$. Whereas some studies have suggested that initial $\mathrm{P}_{\mathrm{aO}_{2}} / \mathrm{F}_{\mathrm{IO}_{2}}$ determined outcome and was lower in non-survivors, ${ }^{22}$ others have shown that initial $\mathrm{P}_{\mathrm{aO}_{2}} / \mathrm{F}_{\mathrm{IO}_{2}}$ did not independently predict outcome.7,23 The current study provides further evidence, based on a more vigorous database and strict definition of ARDS, that the severity of ARDS, as measured by initial $\mathrm{P}_{\mathrm{aO}_{2}} / \mathrm{F}_{\mathrm{IO}_{2}}$, does not predict outcome, and patients should receive the same level of care and lungprotective measures regardless of how mild or severe the initial assessment of ARDS. $\mathrm{P}_{\mathrm{aO}_{2}} / \mathrm{F}_{\mathrm{IO}_{2}}$ is useful in early identification of patients with ARDS, in fulfilling diagnostic criteria to enroll in clinical trials, and to initiate the appropriate therapies for ARDS; however, it should not be used as a predictor of outcome. A more important predictor of outcome may be the direction of $\mathrm{P}_{\mathrm{aO}_{2}} / \mathrm{F}_{\mathrm{IO}_{2}}$ during the course of management of ARDS, as suggested by one study. ${ }^{24}$

The explanation of why there are no differences in outcome in relation to initial severity of ARDS could possibly be due to delay in diagnosis and/or management of ARDS in patients with milder disease, leading to worse outcome. Another explanation is that patients with severe ARDS (lower $\mathrm{P}_{\mathrm{aO}_{2}} / \mathrm{F}_{\mathrm{IO}_{2}}$ at randomization) are more likely to receive protective lung strategies or other interventions that have been shown to improve outcome of ARDS, such as muscle relaxation or proning.

The study has several strengths, including the multicenter prospective database, the robust diagnosis of ARDS, strict definition of severity of ARDS at the time of randomization based on the Berlin criteria, heterogeneous patient population including surgical and trauma, and the therapeutic interventions in these trials. There are few limitations that warrant mention. These include the retrospective analysis of the prospective database and the fact that details about the different etiologies, including microbiology, antibiotic treatment, and type of trauma, are lacking. Also, this study does not provide long-term outcomes of the subjects. Further studies are needed to address these limitations.

\section{Conclusions}

This study provides further insight about predictors of outcome in subjects with ARDS. Despite the importance of $\mathrm{P}_{\mathrm{aO}} / \mathrm{F}_{\mathrm{IO}_{2}}$ in making the diagnosis of ARDS and strati- fying its severity at the time of diagnosis, this study shows that $\mathrm{P}_{\mathrm{OO}_{2}} / \mathrm{F}_{\mathrm{IO}_{2}}$ does not predict outcome of these subjects. Among the etiologies of ARDS; trauma was associated with best survival compared with other causes.

\section{REFERENCES}

1. Villar J, Blanco J, Kacmarek RM. Current incidence and outcome of the acute respiratory distress syndrome. Curr Opin Crit Care 2016; 22(1):1-6.

2. Soubani AO, Shehada E, Chen W, Smith D. The outcome of cancer patients with acute respiratory distress syndrome. J Crit Care 2014; 29(1):183.e7-183.e12.

3. Soubani AO, Chen W, Jang H. The outcome of acute respiratory distress syndrome in relation to body mass index and diabetes mellitus. Heart Lung 2015;44(5):441-447.

4. El-Haddad H, Jang H, Chen W, Haider S, Soubani A. The effect of demographics and patient location on the outcome of patients with acute respiratory distress syndrome. Ann Thorac Med 2017;12(1): 17-24.

5. Luo L, Shaver CM, Zhao Z, Koyama T, Calfee CS, Bastarache JA, Ware LB. Clinical predictors of hospital mortality differ between direct and indirect ARDS. Chest 2017;151(4):755-763.

6. Agarwal R, Srinivas R, Nath A, Jindal SK. Is the mortality higher in the pulmonary vs the extrapulmonary ARDS? A meta analysis. Chest 2008;133(6):1463-1473.

7. Chen W, Janz DR, Shaver CM, Bernard GR, Bastarache JA, Ware LB. Clinical characteristics and outcomes are similar in ARDS diagnosed by oxygen saturation $/ \mathrm{F}_{\mathrm{IO}_{2}}$ ratio compared with $\mathrm{P}_{\mathrm{aO}_{2}} / \mathrm{F}_{\mathrm{IO}_{2}}$ ratio. Chest 2015;148(6):1477-1483.

8. Acute Respiratory Distress Syndrome Network, Brower RG, Matthay MA, Morris A, Schoenfeld D, Thompson BT, Wheeler A. Ventilation with lower tidal volumes as compared with traditional tidal volumes for acute lung injury and the acute respiratory distress syndrome. N Engl J Med 2000;342(18):1301-1308.

9. Brower RG, Lanken PN, MacIntyre N, Matthay MA, Morris A, Ancukiewicz M, et al. Higher versus lower positive end-expiratory pressures in patients with the acute respiratory distress syndrome. N Engl J Med 2004;351(4):327-336.

10. National Heart, Lung, and Blood Institute Acute Respiratory Distress Syndrome (ARDS) Clinical Trials Network, Wiedemann HP, Wheeler AP, Bernard GR, Thompson BT, Hayden D, et al. Comparison of two fluid-management strategies in acute lung injury. N Engl J Med 2006; 354(24):2564-2575.

11. National Heart, Lung, and Blood Institute Acute Respiratory Distress Syndrome (ARDS) Clinical Trials Network, Wheeler AP, Bernard GR, Thompson BT, Schoenfeld D, Wiedemann HP, et al. Pulmonary-artery versus central venous catheter to guide treatment of acute lung injury. N Engl J Med 2006;354(21):2213-2224.

12. Steinberg KP, Hudson LD, Goodman RB, Hough CL, Lanken PN, Hyzy R, et al. Efficacy and safety of corticosteroids for persistent acute respiratory distress syndrome. N Engl J Med 2006;354(16): 1671-1684.

13. National Heart, Lung, and Blood Institute Acute Respiratory Distress Syndrome (ARDS) Clinical Trials Network, Matthay MA, Brower RG, Carson S, Douglas IS, Eisner M, et al. Randomized, placebo-controlled clinical trial of an aerosolized beta(2)-agonist for treatment of acute lung injury. Am J Respir Crit Care Med 2011;184(5):561-8.

14. ARDS Definition Task Force, Ranieri VM, Rubenfeld GD, Thompson BT, Ferguson ND, Caldwell E, et al. Acute respiratory distress syndrome: the Berlin definition. JAMA 2012;307(23):2526-2533.

15. Murray JF, Matthay MA, Luce JM, Flick MR. An expanded definition of the adult respiratory distress syndrome. Am Rev Respir Dis 1988;138(3):720-723. 


\section{EFFect of ARDS SeVerity AND ETIOLOGy on Outcomes}

16. Hudson LD, Milberg JA, Anardi D, Maunder RJ. Clinical risks for development of the acute respiratory distress syndrome. Am J Respir Crit Care Med 1995;151(2 Pt 1):293-301.

17. Treggiari MM, Hudson LD, Martin DP, Weiss NS, Caldwell E, Rubenfeld G. Effect of acute lung injury and acute respiratory distress syndrome on outcome in critically ill trauma patients. Crit Care Med 2004;32(2):327-331.

18. McClintock DE, Matthay MA. Why does acute lung injury have no impact on mortality in patients with major trauma? Crit Care Med 2004;32(2):583-584.

19. Moss M, Gillespie MK, Ackerson L, Moore FA, Moore EE, Parsons PE. Endothelial cell activity varies in patients at risk for the adult respiratory distress syndrome. Crit Care Med 1996;24(11):1782-1786.

20. Eisner MD, Parsons P, Matthay MA, Ware L, Greene K. Plasma surfactant protein levels and clinical outcomes in patients with acute lung injury. Thorax 2003;58(11):983-988
21. Eisner MD, Thompson T, Hudson LD, Luce JM, Hayden D, Schoenfeld D, et al. Efficacy of low tidal volume ventilation in patients with different clinical risk factors for acute lung injury and the acute respiratory distress syndrome. Am J Respir Crit Care Med 2001; 164(2):231-236.

22. Bersten AD, Edibam C, Hunt T, Moran J. Incidence and mortality of acute lung injury and the acute respiratory distress syndrome in three Australian States. Am J Respir Crit Care Med 2002;165(4):443-448.

23. Knaus WA, Sun X, Hakim RB, Wagner DP. Evaluation of definitions for adult respiratory distress syndrome. Am J Respir Crit Care Med 1994;150(2):311-317.

24. Bone RC, Maunder R, Slotman G, Silverman H, Hyers TM, Kerstein MD, Ursprung JJ. An early test of survival in patients with the adult respiratory distress syndrome: the $\mathrm{P}_{\mathrm{aO}_{2}} / \mathrm{F}_{\mathrm{IO}_{2}}$ ratio and its differential response to conventional therapy: Prostaglandin E1 Study Group. Chest 1989;96(4):849-851. 